ISSN 1518-3483

Licenciado sob uma Licença Creative Commons

\title{
Políticas Educacionais para a educação superior e os dilemas das licenciaturas: questões curriculares
}

\section{Educational Policies for higher education and the dilemmas of undergraduate courses: curricular questions}

\author{
Neide Cavalcante Guedes ${ }^{[a]}$, Rita de Cássia Prazeres Frangella ${ }^{[b]^{*}}$ \\ [a] Universidade Federal do Piauí (UFPI) Teresina, PI, Brasil \\ ${ }^{[b]}$ Universidade do Estado do Rio de Janeiro (UERJ) Rio de Janeiro, RJ, Brasil
}

\section{Resumo}

O presente artigo objetiva discutir como as politicas educacionais para o ensino superior tratam os dilemas enfrentados pelos cursos de licenciaturas, considerando que compete à Universidade como lócus de formação, garantir aos futuros profissionais a integração ensino, pesquisa e extensão. Tomamos como foco de investigação as Diretrizes Curriculares para a formação inicial e continuada definidas na Resolução № 2, de 1으 de julho de 2015. Para o desenvolvimento do estudo apresentamos os aportes teóricos que subsidiaram nossas discussões, dando destaque a Lopes e Macedo (2011) e Frangella (2016) a partir

NCG: Doutora em Educação, e-mail: neidecguedes@hotmail.com

RCPF: Doutora em Educação, e-mail: rcfrangella@gmail.com 
das quais assumimos a compreensão sobre o currículo como um processo dialógico cujos sentidos não são e nunca serão transparentes, pois são produzidos em meio à negociação, à articulação. Argumentamos que essa perspectiva nos orienta a empreender análises que, para além de binarismo e dicotomias, se voltem para a articulação, deslocamento entre as diferentes esferas observando como as relações inter e intracontextuais operam.

Palavras-chave: Políticas educacionais. Cursos de licenciaturas. Diretrizes curriculares.

\begin{abstract}
The present article aims to discuss how educational policies for higher education deal with the dilemmas faced by undergraduate courses, considering that is the University's responsibility, as a locus of formation, to guarantee future professionals the integration of teaching, research and extension. We focus on the National curriculum guidelines for initial training and continuing education defined in Resolution No. 2 of July 1, 2015. For the development of the study, we present the theoretical contributions that subsidized our discussions, highlighting Lopes and Macedo (2011) and Frangella (2016) from which we assume the understanding about the curriculum as a dialogical process, whose senses are not and will never be transparent, because they are produced in the midst of negotiation, articulation. We argue that this perspective guides us to undertake analyzes that, in addition to binarism and dichotomies, turn to the articulation, displacement between the different spheres, observing how the inter and intracontextual relations operate.
\end{abstract}

Keywords: Educational policies. Undergraduate courses. Curricular guidelines.

\title{
Introdução
}

A formação de professores, quando discutida como temática, compreende na maioria das vezes, estudos pautados no saber/fazer do professor, na ênfase do processo inicial de ser professor e do continuado de fazer-se docente. Nessa perspectiva, estes processos nos incentivam a 
distinguir a linearidade dessa temática, considerando que, ora é discutida a formação inicial sendo a condição dada ao estudante iniciante (GARCIA, 1992 que não tem experiência em sala de aula, ora a formação continuada a partir do aprimoramento dos conhecimentos práticos e teóricos a fim de se produzir uma prática mais inovadora, reflexiva e transformadora (GUEDES, MONTEIRO, 2011).

Neste artigo objetivamos discutir como as políticas educacionais para o ensino superior tratam os dilemas enfrentados pelos cursos de licenciaturas, considerando que compete à Universidade como lócus de formação, garantir aos futuros profissionais a integração ensino, pesquisa e extensão. As discussões que aqui apresentamos se desdobram de pesquisas por nós desenvolvidas no campo da gestão curricular (GUEDES, 2016) e no campo do currículo (FRANGELLA, 2015, 2016). Tomamos como foco de investigação as Diretrizes Curriculares para a formação inicial e continuada definadas na Resolução $N^{\circ} 2$, de $1^{\circ}$ de julho de 2015.

Os pressupostos teóricos com os quais dialogamos - a teoria do discurso laclauniana e a perspectiva discursivo-cultural de Bhabha nos permitem defender que políticas curriculares se constituem como políticas discursivas, enunciações culturais. Aliado a isso, tomamos a política curricular com ato de significar, estancamento do fluxo de significação. Nesse direcionamento nossa compreensão de currículo se constitui a partir da posição assumida por Frangella (2016, p. 112) ao afirmar que currículo é:

[...] movimento, diferimento, significação. Como produção político-discursiva, o currículo é terreno de luta política pela significação que mobiliza o eu e o outro, ou seja, processo dialógico cujos sentidos não são e nunca serão transparentes, pois são produzidos em meio à negociação, à articulação. O que se produz ao produzir currículo não é uma visão ou outra, mas uma produção híbrida que já não é mais nem um nem outro, à medida que o eu e o outro aí referenciados alusivamente não são inimigos em luta, mas adversários legítimos em disputa. Esse processo contingente é cultural, ato de enunciação cultural. 
As discussões que estabelecemos no movimento de pesquisa são interfaceadas com os autores que discutem numa perspectiva pós-estrutural e pós-colonial, na compreensão de uma prática política e cultural ambivalente e contraditória, que não se articula sem conflitos e embates, mas que se constitui no diálogo, no enfrentamento da diferença (BHABHA, 2003; LOPES e MACEDO, 2011; BARREIROS e FRANGELLA, 2010). Dessa forma, buscamos analisar a produção política que se constitui em consensos, não como arranjo harmônico, mas em meio a conflitos, o que demarca seu caráter de provisoriedade, fruto de articulações políticas contingenciais. Com isso, acreditamos que os textos curriculares são produzidos e contextualizados de acordo com suas demandas; a política curricular não é finalizada e fixada no momento de sua criação. Dessa maneira, adotamos a postura de compreender que "a política curricular é, assim, uma produção de múltiplos contextos sempre produzindo novos sentidos e significados para as decisões curriculares" (LOPES e MACEDO, 2011, p. 274).

Nosso intuito, ao apontar alguns aspectos que provoquem discussões em torno da importância e da necessidade de se rever e ressignificar as políticas voltadas para a formação inicial de professores e suas relações com a escola básica, se alinha a indicação de que esta

[...] situa-se como aspecto central nas formulações de políticas educacionais para a educação básica, sobretudo nas décadas de 1990 a 2000. Assim, as discussões acerca da melhoria dos índices da educação básica, em termos de acesso, permanência e resultados das escolas, têm sido associadas às preocupações sobre formação docente (ENS; GISI e EYNG, 2010, p. 46).

Uma associação que se articula não só à percepção de que mudanças na formação permitiriam, de forma direta, avanços qualitativos o que superficializa a discussão ao não considerar a complexidade do fazer docente enquanto prática político-social - mas também a um contexto em que, na pauta de produção de políticas educacionais, as políticas curriculares ganham centralidade no debate como meio de projeção de qualidade como igualdade, o que seria garantido a partir de um reordenamento 
do paradigma curricular. Isso se observa e articula num contexto de produção e discussão em torno da Base Nacional Comum Curricular (2016). Nesse sentido, é que enfatizamos que a formação de professores precisa ser tratada não como um elemento garantidor de índices para a educação, mas a formação, tanto inicial quanto continuada, precisa ser analisada como parte de um contexto de produção de demandas que permitem o engendramento de políticas educacionais. Para tal, nossas reflexões se desdobram de uma perspectiva discursiva de trabalho, a partir da qual a leitura das políticas curriculares nos permitem compreender como essas desenham o mapa de poderes/relações/saberes produzidos nos embates pela e na formação de professores. Nesse sentido, enfatiza-se ainda mais a problemática da elaboração curricular como central no entendimento das complexas relações entre poder/saber/subjetividades, vendo-as como prática discursiva, de significação.

\section{As novas Diretrizes Curriculares para a formação de professores: projetos em disputa}

A Resolução No 2 , de $1^{\circ}$ de julho de 2015 que define as Diretrizes Curriculares Nacionais para a formação inicial em nível superior no Artigo 10 estabelece que

Art. 10. A formação inicial destina-se àqueles que pretendem exercer o magistério da educação básica em suas etapas e modalidades de educação e em outras áreas nas quais sejam previstos conhecimentos pedagógicos, compreendendo a articulação entre estudos teóricopráticos, investigação e reflexão crítica, aproveitamento da formação e experiências anteriores em instituições de ensino.

Apreciando o texto da Resolução, faz-se necessário considerar dilemas enfrentados pelos cursos de licenciatura desde suas origens e que até hoje não encontraram soluções satisfatórias: um deles diz respeito a não superação do chamado esquema $3+1$ que ainda persiste, e o outro diz 
respeito a dicotomia entre o bacharelado e a licenciatura, considerando que na grande maioria das Universidades brasileiras persiste dentro do mesmo curso essas duas modalidades de formação, o que faz com que a Instituição assuma o objetivo de, além de formar professores, formar, também, e com maior ênfase, o pesquisador.

Observa-se na leitura das DCNs, nos considerando que sustentam a Resolução a indicação de ideias que são centrais às proposições:

CONSIDERANDO que a igualdade de condições para o acesso e a permanência na escola; a liberdade de aprender, ensinar, pesquisar e divulgar a cultura, o pensamento, a arte e o saber; o pluralismo de ideias e de concepções pedagógicas; o respeito à liberdade e o apreço à tolerância; a valorização do profissional da educação; a gestão democrática do ensino público; a garantia de um padrão de qualidade; a valorização da experiência extraescolar; a vinculação entre a educação escolar, o trabalho e as práticas sociais; o respeito e a valorização da diversidade étnico-racial, entre outros, constituem princípios vitais para a melhoria e democratização da gestão e do ensino;

CONSIDERANDO o currículo como o conjunto de valores propício à produção e à socialização de significados no espaço social e que contribui para a construção da identidade sociocultural do educando, dos direitos e deveres do cidadão, do respeito ao bem comum e à democracia, às práticas educativas formais e não formais e à orientação para o trabalho;

No entanto, olhando mais atentamente para o documento encontramos uma perspectiva de currículo que considera apenas as relações entre os conteúdos e suas respectivas cargas horárias conforme descrito no artigo 12 onde estão definidos os núcleos de estudos e aprofundamentos e que vai se complementar com o disposto no artigo 13, que orienta a formação inicial e continuada de professores tendo como princípio estruturante a garantia de uma base comum nacional das orientações curriculares.

Associar a definição de uma base à condição de conquista de qualidade e estabelecimento de metas, desloca o significado tanto de qualidade quanto de base comum, que então figura não com a perspectiva de 
indicação de princípios básicos de qualificação da docência, mas transmuta-se em marco regulatório.

O que se observa é a tensão e a luta entre dois projetos de formação que se voltam para a mesma noção: a base comum nacional. A luta pelo preenchimento de significação da ideia de base se evidencia nas contradições percebidas na leitura da DCN.

Por um lado, há uma ênfase em processos de controle e regulação com a indicação da definição de metas claras sobre o que é qualidade. Tanto é, que a incidência da expressão "padrão de qualidade" na parte inicial do texto, onde se indica concepções que orientam a formação é recorrente, por outro lado, vê-se reverberar a defesa feita pela ANFOPE desde a década de 1990 na docência como base da formação, marcada por uma perspectiva crítica em que se enfatiza na definição de princípios básicos que qualificariam a docência e, por conseguinte, o educador: uma sólida formação teórica, compromisso social, unidade entre teoria/prática.

Art $1^{\circ}$. $\S 2^{\circ}$ As instituições de ensino superior devem conceber a formação inicial e continuada dos profissionais do magistério da educação básica na perspectiva do atendimento às políticas públicas de educação, às Diretrizes Curriculares Nacionais, ao padrão de qualidade e ao Sistema Nacional de Avaliação da Educação Superior (Sinaes), manifestando organicidade entre o seu Plano de Desenvolvimento Institucional (PDI), seu Projeto Pedagógico Institucional (PPI) e seu Projeto Pedagógico de Curso (PPC) como expressão de uma política articulada à educação básica, suas políticas e diretrizes.

Art. $5^{\circ} \mathrm{A}$ formação de profissionais do magistério deve assegurar a base comum nacional, pautada pela concepção de educação como processo emancipatório e permanente, bem como pelo reconhecimento da especificidade do trabalho docente, que conduz à práxis como expressão da articulação entre teoria e prática e à exigência de que se leve em conta a realidade dos ambientes das instituições educativas da educação básica e da profissão.

Contudo, na disputa de sentidos e na articulação com a ideia de qualidade, o que se sobressai é o atrelamento da sólida formação à 
definição de padrões de qualidade, como se observa no desdobramento do artigo 5:

$\S 5^{\circ}$ São princípios da Formação de Profissionais do Magistério da Educação Básica:

I a formação docente para todas as etapas e modalidades da educação básica como compromisso público de Estado, buscando assegurar o direito das crianças, jovens e adultos à educação de qualidade, construída em bases científicas e técnicas sólidas em consonância com as Diretrizes Curriculares Nacionais para a Educação Básica; [...]

IV a garantia de padrão de qualidade dos cursos de formação de docentes ofertados pelas instituições formadoras;

$\mathrm{V}$ a articulação entre a teoria e a prática no processo de formação docente, fundada no domínio dos conhecimentos científicos e didáticos, contemplando a indissociabilidade entre ensino, pesquisa e extensão; [...] (grifo nosso).

O que é possível inferir, a partir de tal leitura, é a constituição de uma cadeia discursiva que negocia sentidos e os disputa em direção a uma produção de política curricular em que se evidencia a centralidade do conhecimento nessa discussão, numa secundarização de aspectos caros às defesas feitas pela ANFOPE que alinham a uma discussão com forte vínculo social e de caráter emancipatório. Não defendemos aqui que se trata de uma polarização em que seja necessário - o que não cremos nem ser possível - defender ora o conhecimento científico-didático ou uma visão contextual problematizadora, o que nos afastaria também das defesas que fazemos do entendimento do currículo como processo de negociação e daí:

negociação (neg [não] + otium [ócio, repouso]) [...] Desvelamento do sujeito humano como agente [...]; a negociação é a habilidade de articular diferenças no espaço e tempo, de ligar palavras e imagens em novas ordens simbólicas, de intervir na floresta de sinais e de mediar o que parece ser valores incomensuráveis ou realidades contraditórias (BHABHA, 2011, p. 97). 
Voltamo-nos para o contexto de produção das DCN: tempos de bases vistas como parâmetros de qualidade que, numa associação de democracia à igualdade, subverte a defesa por unidade em unicidade. Daí pôr a centralidade do conhecimento em debate. Conhecimento se constrói não só balizado em conhecimentos científicos, mas como produção cultural, se enraíza numa determinada concepção de cultura que demarca relações/posições de poder. Isso também fixa uma determinada posição que obscurece as possibilidades de diálogos com as diferenças, de forma a rasurar identificações absolutas. Que sentido se dá ao conhecimento? Quando este se desvincula da produção cultural cotidiana, se encerra no academicismo, abre a fenda intransponível de tantos pertencimentos e identidades reduzidos e condensados, regulados pelo saber.

Alguns autores (DOURADO, 2016; BRZEZINSKI, 2015) chamam atenção para o que destacam como avanços na proposição das DCN: a organicidade de um projeto de formação, a própria definição de base comum, a articulação com a educação básica. Chamamos atenção, na leitura que fazemos, das tensões/problematizações possíveis/passíveis às proposições apresentadas.

\section{Outras leituras possíveis?}

Na busca pela superação das diretrizes propostas anteriormente, o que se observa no documento atual são currículos organizados no sentido de privilegiar a tematização dos conhecimentos escolarizados, dos saberes da experiência e dos processos de iniciação científica.

Acerca disso, observamos que a ênfase na pesquisa e a questão da articulação com a educação básica rompe com hierarquizações, e, nesse contexto, abrem-se possibilidades do fortalecimento das ações coletivas, de espaços de diálogo, onde outros interlocutores vão colocando, abrindo novas agências dos sujeitos envolvidos no processo educacional.

As novas diretrizes apresentam uma perspectiva nova ao estabelecer que: 
Art. 13. Os cursos de formação inicial de professores para a educação básica em nível superior, em cursos de licenciatura, organizados em áreas especializadas, por componente curricular ou por campo de conhecimento e/ou interdisciplinar, considerando-se a complexidade e multirreferencialidade dos estudos que os englobam, bem como a formação para o exercício integrado e indissociável da docência na educação básica, incluindo o ensino e a gestão educacional, e dos processos educativos escolares e não escolares, da produção e difusão do conhecimento científico, tecnológico e educacional, estruturam-se por meio da garantia de base comum nacional das orientações curriculares.

Essa proposição direciona as discussões para um contexto mais amplo, que se constitui no trabalho do educador, considerando o binômio teoria/prática como principal elemento de articulação do currículo, e que nos remete a realidade na qual o trabalho pedagógico se operacionaliza sem esquecer a pesquisa como elemento fulcral para a formação do profissional da educação.

O trabalho associado à pesquisa altera consideravelmente o modelo formativo vigente nas universidades. Essa compreensão encontra-se definida no Artigo $5^{\circ}$ Inciso II das Diretrizes Curriculares ao estabelecer que

II à construção do conhecimento, valorizando a pesquisa e a extensão como princípios pedagógicos essenciais ao exercício e aprimoramento do profissional do magistério e ao aperfeiçoamento da prática educativa;

É possível apreender que a questão da qualidade da formação de professor está vinculada a dois aspectos: o ensinar e o pesquisar. Se por um lado destacamos a centralidade do conhecimento, paradoxalmente, a dimensão da pesquisa articulada a discussão com a educação básica - com e não sobre, condição sine qua non para o que aqui argumentamos - , traz uma perspectiva que pode tencionar e abrir outras possibilidades/potências para o desenho de um projeto formativo, tal como defendemos, ancorado numa perspectiva democrática de 
negociação. Uma prática não está apenas pré-determinada por estruturas hegemônicas, mas sim, são práticas que negociam com estruturas contingenciais de poder. Se informada por uma perspectiva dialógica, a articulação entre formação/educação básica/pesquisa pode evidenciar essa dimensão contingencial.

Como estabelece as Diretrizes curriculares, o conhecimento apreendido pelo licenciando precisa, necessariamente, estar associado aos outros elementos que compõem, na universidade, o tripé ensino, pesquisa e extensão. No campo da formação de professores, Diniz-Pereira (2010, p. 158) ressalta:

[...] os professores torna-se-ão melhores naquilo que fazem por meio da condução de investigações de suas próprias práticas e que a qualidade da aprendizagem dos alunos será melhor. [...] que a pesquisa dos educadores estimulará mudanças positivas na cultura e na produtividade das escolas [...].

Desse modo, Ensino, Pesquisa e Extensão compõem uma tríade a qual incidem nas múltiplas relações que poderão ocorrer na educação e, se considerarmos esses componentes a partir de uma dimensão social, podemos prever que esses se articulam, na tentativa de solidificar a reflexão sobre a prática, nos distintos âmbitos: as disciplinas de graduação, as atividades de extensão ou as pesquisas realizadas sobre a temática, e isso torna relevante considerar a necessidade de articular as diferentes dimensões que constituem essa tríade, sempre e conjuntamente com o professor e não para o professor, uma vez que esse profissional é o autor legitimo de sua prática e, como tal, autorizado a pesquisá-la.

\section{Considerações, ainda que parciais...}

Analisar a formação docente no contexto das políticas exige a compreensão de que essas são políticas culturais, isso porque a política 
educacional envolve mecanismos diversos. Nessa perspectiva, Cury (2002, p. 147) esclarece que as políticas educacionais,

Vem se constituindo hoje em um terreno pródigo de iniciativas quer no campo dos suportes materiais, quer no campo dos suportes institucionais, quer no setor propriamente pedagógico. Elas abrangem, pois, desde a sala de aula até os planos de educação de largo espectro.

Portanto, compreender a função do professor no contexto educacional repercute diretamente na análise de sua formação e nos faz pensar mais amplamente sobre o tema, uma vez que sua função não se refere, somente, a atuação direta em sala de aula, mas necessita contemplar outros contextos.

Pimenta (2003) enfatiza a importância do investimento tanto na formação docente quanto no desenvolvimento profissional desse, isso porque o professor não pode ser considerado apenas como cumpridor de decisões externas ao seu fazer cotidiano. Nessa perspectiva Nóvoa (1992, p. 25) vem corroborar as ideias da citada autora ao enfatizar que

A formação do professor não se constrói por acumulação (de curso, de conhecimentos ou de técnicas), mas sim através de um trabalho de reflexividade crítica sobre as práticas e de re (construção) permanente de uma identidade pessoal.

Pensar a formação docente a partir dessa perspectiva se apresenta como possibilidade de intervenção, no sentido de reafirmar o protagonismo docente nesse setor apesar de os seus processos de elaboração e de gestão seguirem outro caminho, como esclarecem Stoer e Magalhães (2005, p. 17) ao afirmarem que

O paradigma da elaboração de políticas, da tomada de decisão e da implementação das políticas parece ter consistido numa espécie de 
gestão da mudança social de cima para baixo, quer dizer um centro, mais ou menos "iluminado" elaboraria planos de mudança social que depois de implementados teriam efeitos na vida social.

Nesse sentido é oportuno enfatizar que as mudanças educacionais praticadas no país se orientam com base na política de reforma do Estado, e isso faz com que a qualidade da educação, questão mobilizadora e que reforçamos e reconhecemos sua importância, seja discutida de forma ampla, considerando a complexidade do trabalho pedagógico, que não pode ser reduzido a indicadores/metas universalizantes, sob pena de, na fixidez desses indicadores, obliterar o sentido de autoria do trabalho pedagógico que possa se desdobrar da ênfase na pesquisa como eixo de articulação da formação. Associa-se a isso também a desconsideração das diferenças das demandas locais como legítimas. Se a questão da qualidade é uma preocupação social que exige o envolvimento de todos (atores sociais, dos órgãos e governamentais) com vistas a melhoria da educação, passando a ser "entendida como função pública" (SCHEIBE, 2008, p. 41), isso quer dizer que, não basta se pensar em implementar políticas de formação sem levar em conta o cenário que o professor passou e/ou passa, pois quem vive e sofre todos esses impactos que tem como intuito trazer "mudanças" são os professores que realmente sabem suas necessidades.

Esse cenário revela que as discussões no campo do currículo estão em evidência no conjunto de documentos elaborados pelas escolas, bem como nas propostas apresentadas pelos diferentes Sistemas que evocam um entendimento da produção contínua que se dá o currículo e então, dão sentidos ao nosso olhar diante de eventos que, certamente não são neutros e tão pouco isolados de um contexto mais amplo. Defendemos a necessidade de empreender análises que, para além de binarismo e dicotomias, se volte para a articulação, deslocamento entre as diferentes esferas observando como as relações inter e intracontextuais operam. O que é construído e o que é silenciado nesse fluxo de hibridização?

Defendemos, ainda, a possibilidade de se repensar uma formação que seja capaz de instituir políticas mais flexíveis, principalmente se 
considerarmos o panorama social e político atual, que levem em conta o papel do professor e da dinâmica formativa que se pretende assegurar a esse profissional, uma vez que duas possibilidades se apresentam: a primeira que concebe a formação centrada no fazer docente, evidenciando dessa forma sua formação prática, e a segunda que idealiza a formação teórica centrada no saber. A dicotomia que aí se estabelece provoca contextos diversos no campo de atuação do docente que pouco, ou quase nada, contribui para a efetivação da formação docente que garanta articular teoria/prática.

Assim, nossa intenção de problematizar a política curricular para a formação de professores se alinha ao que Lopes (2014) afirma:

Defendo que ampliar o entendimento de política como uma luta por significação nossa afasta da tentativa vã de nos crermos coesos e seguros do futuro que estamos construindo e nos empodera, assim como também nos torna responsáveis pelos atos de transformação social não só no executivo, legislativo, nas ruas, se não em todos os contextos sociais (p. 127).

Com isso em vista, pensamos ser esta uma contribuição da análise que propusemos: deslocar significações acerca de políticas curriculares para a formação, trazendo elementos outros para pensar a formação como possibilidade de acessar e discutir os processos políticos ensejados na ação, adensando o debate acerca da docência como agência e contingência.

\section{Referências}

BHABHA, H. O local de cultura. Belo Horizonte: UFMG, 2003

BHABHA, H. O Bazar global e o clube dos cavalheiros ingleses. Rio de Janeiro: Rocco, 2011.

BARREIROS, D. \& FRANGELLA, R. DE C. Um novo olhar sobre o sentido de política nos estudos curriculares. Roteiro (revista da UNOESC). Joaçaba, UNOESC, v. 35, p. 231-250, 2010. 
BRASIL. Resolução CNE/CP $n^{0}$ 2, de $1^{0}$ de julho de 2015 - Define as Diretrizes Curriculares Nacionais para a formação inicial em nível superior (cursos de licenciatura, cursos de formação pedagógica para graduados e cursos de segunda licenciatura) e para a formação continuada.

BRZEZINSKI, I. Diretrizes para a formação docente: desafios e perspectivas. Painel apresentado na Universidade Tecnológica Federal do Paraná, 2015

CURY, C. R. J. Políticas da educação: um convite ao tema. In: FAVERO, O.; SEMERARO, G. (Orgs.). Democracia e construção do público no pensamento educacional brasileiro. São Paulo: Vozes, 2002.

DOURADO, L. Formação de profissionais do magistério da educação básica: novas diretrizes e perspectivas. Comunicação \& educação. SP/USP. Ano XXI n. 1, jan./jun. 2016.

GARCIA, M. Formação de professores: novas perspectivas baseadas na investigação sobre o pensamento do professor. In: NÓVOA, A. Os professores e a sua formação. Lisboa: Publicações Dom Quixote, 1992.

DINIZ- PEREIRA, J. E. A epistemologia da experiência na formação de professores: primeiras aproximações. Revista Brasileira de Pesquisa sobre Formação Docente, Belo Horizonte, 2010.

ENS, R. T.; GISI, M. L.; EYNG, A. M. Profissão docente em questão: tensões e desafios. In: ENS, R. T.; BEHRENS, M. A. Formação do professor: profissionalidade, pesquisa e cultura escolar. Curitiba: Champagnat, 2010.

FRANGELLA, R. de C. Políticas de formação do alfabetizador e produção de políticas curriculares: pactuando sentidos para formação, alfabetização e currículo. Práxis Educativa, Ponta Grossa, v. 11, n. 1, p. 107-128, jan./abr. 2016

FRANGELLA, R. C. P.; CINELLI, M. L. S. V.. Interrogando a Base Nacional Comum Curricular e as perspectivas para a formação de professores. In: PEREIRA, M. Z; ALBINO, A. C.; DANTAS, V. X. (Org.). Políticas de Currículo e formação: desafios contemporâneos. 1ed. João Pessoa: Editora UFPB, 2015. p. 34-51.

GARCÍA, C.M. Formação de professores: para uma mudança educativa. Porto: Porto Editora, 1999. 
GUEDES, N. C; MONTEIRO, A. L. Formação continuada: o conceito e suas implicações na atividade docente. Piauí: UFPI, 2011. (Comunicação oral).

GUEDES, N. C. Gestão Curricular e os Cenários Contemporâneos: processos formativos de estudantes do curso de Licenciatura em Artes Visuais da Universidade Federal do Piauí. Projeto desenvolvido em Estágio Pós-Doutoral no âmbito do Programa de Pós-Graduação em Educação da Universidade do Estado do Rio de Janeiro, Rio de Janeiro, 2016

LOPES, A. C. Políticas curriculares: continuidade ou mudança de rumos? Revista Brasileira de Educação. n. 26, mai./jun. /jul. /ago., 2004.

LOPES, A. No habrá paz en la politica. Debates y Combates. Tucumán, Universidad de San Pablo/Fundación Casa del Pueblo, n. 6, may., 2014.

LOPES, A.C.; MACEDO, E (a). Teorias de Currículo. São Paulo: Cortez, 2011.

NÓVOA, A. Os professores e a sua formação. Lisboa: Publicações Dom Quixote, 1992.

PIMENTA, S. G. (Org.). Saberes pedagógicos e atividade docente. São Paulo: Cortez, 2003.

SCHEIBE, L. Valorização e formação dos professores para a educação básica: questões desafiadoras para um novo plano nacional de educação. Educação \& Sociedade., Campinas, v. 31, n. 112, p. 981-1000, 2008.

STOER, S.; MAGALHÃES, A. A diferença somos nós. A gestão da mudança social e as políticas educativas e sociais. Porto: Edições Afrontamento, 2005.

Recebido: 22/06/17

Received: 06/22/2017

Aprovado: 27/07/17

Approved: 07/27/2017 